same way as already described. In case of myopia the marks on A should be brought forward $1 \mathrm{~mm}$. for every three dioptres, and in case of hypermetropia correspondingly displaced backwards. Again, these allowances are to be made only for points behind the equator, and if in a myopic eye they should bring the marks across this plane, the part which brings them up to this ordinate is alone to be allowed.

The modified markings, of course, do not give the relationship to the anterior hemisphere; if this is wanted, the original positions will show it.

The allowance for variations of depth of the anterior chamber also is made by placing the marks correspondingly forwards or backwards in establishing the relationship to the iris, posterior chamber, and lens.

The following information can at once be read from the charts:

1. The distance of the foreign body from the periphery.

2. Its relation to any of the structures within the eveball.

3. The meridian in which it lies.

4. Its distance behind any particular point, such as the limbus.

In addition, the three measurements originally supplied are recorded.

The value of an exact localization of a foreign body, beyond the ascertainment whether it is within the globe, is, I believe, often underrated. But for magnetic extraction by the anterior route also I am convinced that it is often of great service. For extraction through a scleral wound it is obvious that it is a guide to the direction in which magnetic traction will act to greatest advantage in disentangling from adhesions, and to the direction which will, if possible, avoid entanglement in the ciliary region, or undue injury to the lens and its supporting ligaments.

Before concluding this paper I wish to express my thanks to Colonel W. T. Lister, C.M.G., consulting ophthalmic surgeon to the British Expeditionary Force, for his kind interest and advice, particularly with regard to the preparation of the two final charts.

\title{
NOTES
}

\section{A NOTE ON CATARACT EXTRACTION, WITH A SUGGESTION}

BY

I. Herbert Fisher, LONDON.

FOR the extraction of cataract it is my practice to do the combined operation with iridectomy, usually at a single sitting, and I only quite rarely perform a simple extraction. 
At my visit to the hospital some thirty hours after extraction of a cataract, about two or three months ago, I found the pupil of my patient fully and quite circularly dilated, the aqueous chamber being well re-formed. I assumed that atropin had been used at the first dressing of the case by the house surgeon, some six hours earlier, but I was informed by my house officer, as well as by the sister of the ward, that the pupil was in this condition when the pads were removed for the first time, and that no mydriatic of any kind had been used. It seemed to me perfectly obvious that this result could only have been obtained if a drop of atropin had been put into the eye when the patient was on the operating table, twenty-four hours earlier, by mistake, when it had been intended to use cocain.

Investigation by the sister subsequently proved that this was the case. The pupil remained absolutely wide, circular, and immobile, without any further instillation of atropin for some three or four days. This result seemed so promising and advantageous, that since I thus accidentally stumbled upon what appears to me to be a very practical advantage, I have made it my practice when the eye has been prepared for operation and after the speculum has been introduced, to place one or two drops of one per cent. or half per cent. sterilised sulphate of atropin into the conjunctival sac, and at once proceed to make my section. In every case the same result has followed-before the completion of the operation the pupil is observed to be yielding widely and circularly, and, if the healing proceeds normally, the pupil will be found in this condition, dilated ad maximum, and will remain so, without further use of mydriatic, for three or four days.

In one recent case, where at its highest point the section was just within the limbus, healing proceeded slowly, and aqueous was not satisfactorily retained for the greater part of a week; some soft lens matter was also left behind, but the pupil was absolutely wide and circular. In such a case it seems likely that when the aqueous chamber did re-form, at so late a.date, attachments might have been found between the iris and lens capsule, if the usual method of using atropin when aqueous had collected had been resorted to. This case is still under observation, and is doing as satisfactorily as all the others. This little modification of method appears to me to be quite unobjectionable, and likely to be attended by the very good result of reducing, if not abolishing, the number of cases of updrawn pupil following extraction, which demand a difficult and sometimes fruitless subsequent operation. It relieves the surgeon of one of his most serious anxieties. In none of my cases has there been any iritis to contend with. It diminishes the amount of disturbance to which the patient and the eye in the early post-operation stages have to be subjected: frequent dressings and repeated instillations of atropin can be avoided for two or three days at least. 
I have used it also with satisfactory result in the performance of iridectomy, whether preliminary to extraction or for other reasons; not of course in glaucoma cases. There appears to me to be only one possible contra-indication and that obviously would be in the case of a patient known to have suffered from local atropin irritation; fortunately, in my experience in all cases, the conjunctiva will tolerate atropin for a considerable period of time, unless it has previously suffered from this complication.

Obviously, when the atropin solution is dropped into the conjunctival sac, and the section immediately proceeded with, the alkaloid in very considerable strength must make its way into contact with the iris, and in a strength out of all proportion greater than that which we can ever get by the usual methods of application in the after-treatment of a cataract case.

The BRITISH JouRnal of Ophthalmology has so wide a circulation that $\mathrm{I}$ have thought it wise to bring a short note of this procedure before its readers, in the hope that many operators will test its efficacy, and possibly, at a later date, express their opinion upon it. I cannot but think that it is a very practical and simple way of improving our results in cataract extraction.

\title{
INJURY TO THE EYE, COMPLICATED WITH ABSCESS OF THE BRAIN AND TERMINATING FATALLY; AUTOPSY : TWO CASES
}

BY

\author{
G. Victor Miller, M.D.,
}

OPHTHALMIC AND AURAL SURGEON TO THE STOCKTON AND THORNABY HOSPITAL AND NORTH ORMESBY HOSPITAL, MIDDLESBROUGH.

1. A boy, aged 9 years, when playing football on Saturday, November 4, 1916, fell down. Whilst lying on the ground he received a kick from another boy over the right eye. He was dazed by the force of the blow, but not rendered unconscious. He walked home and there had his eye bathed. His parents continued this treatment until the morning of Tuesday, November 7, 1916, when they decided to take him to the Stockton and Thornaby Hospital, as his eye did not seem to be progressing favourably. The patient walked into the out-patient department at $10.30 \mathrm{a} . \mathrm{m}$. on Nov. 7 suffering from an injury to the right eye, and was seen by the house surgeon. On examination, the right upper and lower eyelids were seen to be markedly swollen and dark-coloured due to effusion of blood. There was a small laceration of the upper lid at the inner canthus and there was a slight exudation of pus from beneath the upper lid at its inner end. The eyeball itself seemed uninjured and 